\title{
STRATEGIC ANALYSIS OF COMMUNITY PARTICIPATION IN PRIMARY HEALTH CARE IN IRAN AND PRESENTATION OF PROMOTION STRATEGIES USING INTERNAL AND EXTERNAL ENVIRONMENT ASSESSMENT TECHNIQUES
}

\author{
Hadi Karimi Nodehil, Nader Khalesi', Amir Ashkan Nasiripourl. Pouran Raeissi Dehkordi2 \\ 1. Department of Health Services Management, Semnan Branch, Islamic Azad University, Semnan, Iran \\ 2. Department of Health Services Management, School of Health Management and Medical Information Science, Iran University \\ of Medical Sciences, Tehran, Iran
}

Correspondence: Nader Khalesi, Email: Khalesi_nader@yahoo.com

\begin{abstract}
\section{INTRODUCTION}

Community participation in health affairs and especially in the field of primary health care is one of the requirements for achieving the goals defined in this field. Accordingly, the present study was designed and implemented with the aim of strategic analysis of the internal and external environment in the field of primary health care in Iran and presentation of the promotion strategies to attract community participation.
\end{abstract}

\section{METHODS}

This is a qualitative study that was conducted using the internal and external environment assessment technique called Strengths, Weaknesses, Opportunities, and Threats (SWOT). The data used were obtained through a semi-structured quality questionnaire and a survey on strengths and weaknesses, opportunities, and threats, as well as proposed promotion strategies to improve community participation in the field of primary health care.

\section{RESULTS}

Analysis of external environment of the field of primary health care in Iran regarding community participation led to identification of the opportunities such as increasing community literacy. The possibility of using public spaces and media as well as influential people to attract community participation. Threats such as financial and employment constraints of families, citizens' unfamiliarity with their effective role in health, and inadequate intersectoral participation. The evaluation of the internal environment led to the identification of strengths in such as native selection policy for health workers; and weaknesses such as lack of attention to evidence-based performance and poor time access to health activities.

\section{CONCLUSION}

The findings of the present study indicate that there are internal weaknesses and external threats to community participation in the field of primary health care.

\section{KEYWORDS:}

Primary health care, Community participation, Strategic analysis 
Today, the issue of health promotion with emphasis on people's participation has received a lot of attention, and the international community expects countries to do the same. [1, 2] Primary health care (PHC) refers to those health services that are provided to the community during their first contact with the health system. [3, 4] In recent years, the issue of health promotion has become more necessary and accepted by emphasizing the role of people in health development. Despite, emphasis and attention at the international level, the Iranian health care system has not achieved much success in attracting active and effective community participation in the health field due to limited citizen participation in community health affairs, especially in relation to health care and major challenges in this regard. [8-10] It should also be noted that it seems that the epidemiological approach that used to be the basis for assessing health needs is no longer responsive to meet the needs and challenges facing the health system, especially primary health care, and the is a need for an approach called participatory approach (based on demand, needs, and perspectives of interested partners including professionals, policymakers, patients, and the general public) with an emphasis on a culture of participation. [12] The present study was designed and implemented with the aim of strategic analysis of the internal and external environment of primary health care in Iran and presentation of promotion strategies to attract community participation. SWOT analysis is considered as one of the most common tools for analyzing internal factors (strengths, weaknesses) and external factors (opportunities and threats) in the organization. The main purpose of SWOT analysis is to move forward based on strengths, minimize weaknesses, seize opportunities, and reduce threats. Internal analysis enables the organization to identify its competencies and weaknesses.

\section{METHODS}

This qualitative study was conducted on 25 health policy makers (head of the network, head of the health centre) from January to October 2019. Purposeful sampling method was used to select participants. Inclusion criteria included having at least 15 years of experience in the health system. Data collection was carried out using semistructured interviews. The interviews lasted between 45 and

60 minutes using an electronic recorder. The interview site was a quiet room in the health centre.

At this stage, the data collection tool included a semistructured qualitative interview guide. Literature review as well as in-depth interviews were used to design the interview guide. This guide could be updated during the interviews. In other words, the researcher conducts additional interviews with previous people so that everyone can answer all the guide questions.

Data collection method: Before conducting all interviews with the participants, prior coordination was conducted by phone or in person. After providing the necessary explanations about the research objectives and its importance and necessity and obtaining informed and voluntary consent from participants, the interviews were conducted. SWOT technique or matrix is a tool for identifying threats and opportunities in the external environment of a system and recognizing its internal strengths and weaknesses to assess the situation and formulate a strategy to guide and control the system. [13]

Steps of SWOT analysis include determining the objectives of the analysis, identifying the strengths and weaknesses of the organization (resources and capabilities), identifying opportunities and threats in the micro and macro external environment, as well as assessing the interaction of strengths and weaknesses against opportunities and threats to develop effective strategies. [16, 17]

This study was approved by the Islamic Azad University of Semnan with the Code of Ethics:

IR.IAU.Semnan.REC.1396.4. Written and oral consent form were received from all participants before interviews. Participants were assured that their information would remain confidential and that they could withdraw from the study at any time.

\section{RESULTS}

According to the purpose of the present study, its findings can be presented in five main areas of strengths, weaknesses, opportunities, and threats related to community participation in primary health care, as well as promotional suggestions for appropriate strategic management in this area. The findings related to each of these areas are mentioned in detail below in Table 1, 2 


\begin{tabular}{|c|c|}
\hline OPPORTUNITIES & THREATS \\
\hline $\begin{array}{l}\text { - Relatively increasing literacy of the public people } \\
\text { and their increasing potential for effective } \\
\text { participation } \\
\text {-The possibility of using public spaces } \\
\text { (neighborhoods, schools, mosques, etc.) in } \\
\text { programs related to community participation } \\
\text { - The possibility of using mass media to educate } \\
\text { the public and encourage them to participate } \\
\text { - The possibility of financial participation of } \\
\text { philanthropists, especially in the provision of spaces } \\
\text { and health equipment } \\
\text { - The possibility of using communities such as Friday } \\
\text { prayers, religious ceremonies, charity food, etc. in } \\
\text { order to educate the public and attract their } \\
\text { participation }\end{array}$ & $\begin{array}{l}\text { - Low-income status of men and lack of enough } \\
\text { time to participate in health affairs } \\
\text {-Impossibility for women's active participation due } \\
\text { to their family concerns } \\
\text { - Irrational expectations and financial and political } \\
\text { abuses of some philanthropists } \\
\text { - Lack of a suitable cultural, social, etc. context for } \\
\text { people's participation } \\
\text { - Lack of awareness of people about their rights } \\
\text { and effective role in health issues } \\
\text {-Lack of appropriate laws and policies to support } \\
\text { and promote community participation in the } \\
\text { health field } \\
\text { - Inadequate intersectoral cooperation between } \\
\text { different departments in the health field }\end{array}$ \\
\hline
\end{tabular}

TABLE 2: ANALYSIS OF THE INTERNAL ENVIRONMENT OF THE PRIMARY HEALTH CARE SYSTEM REGARDING COMMUNITY PARTICIPATION

\section{STRENGTHS}

- The effective role of health center officials in attracting community participation

- Selection of health personnel from native forces and familiar with native culture

-The effective role of health liaisons and ambassadors

- Physical access of people to health workers, liaisons, and ambassadors

- Providing the potential to attract community participation in health programs from a hardware and software perspective

\section{WEAKNESSES}

- Lack of understanding of health conditions and needs by the relevant authorities

-Lack of knowledge and skills in some managers and health personnel in attracting the community participation and especially philanthropists

- Lack of research to assess resources and identify deficiencies and needs

-Lack of written and transparent guidelines regarding community participation in health affairs - Political abuses of people's participation and gatherings

- Short access to health centers and non-

participation of employed people due to their job affairs

- Lack of manpower providing services in order to attract community participation 
SWOT analyses performed based on the interaction field, and SO, WO, ST and WT domains consisted of 6, 5, 5 between the internal and external environment of the and 2 strategies, respectively (Table 3 ).

TABLE 3: PROMOTION STRATEGIES DETERMINED BASED ON THE INTERACTION OF INTERNAL AND EXTERNAL FACTORS

\begin{tabular}{|c|c|c|}
\hline & & EXTERNAL ENVIRONMENT \\
\hline $\begin{array}{l}\text { INTERNAL AND } \\
\text { EXTERNAL } \\
\text { FACTORS }\end{array}$ & 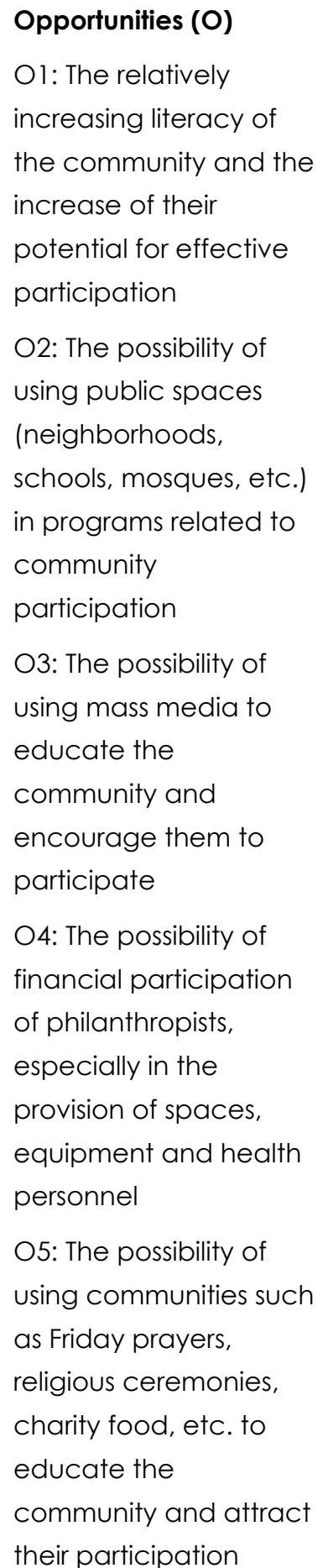 & $\begin{array}{l}\text { Threats (T) } \\
\text { T1: Low-income status of men and lack of enough time } \\
\text { to participate in health affairs } \\
\text { T2: Impossibility for women's active participation due to } \\
\text { their family concerns } \\
\text { T3: Irrational expectations and financial and political } \\
\text { abuses of some philanthropists } \\
\text { T4: Lack of a proper sociocultural context for public } \\
\text { participation } \\
\text { T5: Lack of awareness of people about their rights and } \\
\text { their effective role in health issues } \\
\text { T6: Lack of appropriate laws and policies to support and } \\
\text { promote community participation in the health field } \\
\text { T7: Inadequate intersectoral cooperation between } \\
\text { institutions in the health field }\end{array}$ \\
\hline
\end{tabular}




\begin{tabular}{|c|c|c|c|}
\hline $\begin{array}{l}\text { INTERNAL } \\
\text { ENVIRONMENT }\end{array}$ & $\begin{array}{l}\text { Strengths (S) } \\
\text { S1: The effective role of } \\
\text { health center officials in } \\
\text { attracting community } \\
\text { participation } \\
\text { S2: Selection of health } \\
\text { personnel from native } \\
\text { forces and familiar with } \\
\text { native culture } \\
\text { S3: The effective role of } \\
\text { health liaisons and } \\
\text { ambassadors } \\
\text { S4: Physical access of } \\
\text { people to health } \\
\text { workers, liaisons, and } \\
\text { health ambassadors } \\
\text { S5: Providing the } \\
\text { potential to attract } \\
\text { community } \\
\text { participation in health } \\
\text { programs from a } \\
\text { hardware and software } \\
\text { perspective }\end{array}$ & $\begin{array}{l}\text { SO strategies } \\
\text { S5O1: Empowering the } \\
\text { public and people who } \\
\text { are willing to participate } \\
\text { in health-related } \\
\text { activities } \\
\text { S2O3 and S1O2: } \\
\text { Encouraging the public } \\
\text { to participate in } \\
\text { community health issues } \\
\text { through the mass media } \\
\text { as well as influential } \\
\text { people, especially in } \\
\text { communities } \\
\text { S2O2: Using public } \\
\text { facilities and spaces to } \\
\text { attract community } \\
\text { participation } \\
\text { S3O1: Increasing the } \\
\text { knowledge and skills of } \\
\text { health liaisons and } \\
\text { ambassadors } \\
\text { S1O4: Leading } \\
\text { philanthropists to } \\
\text { community health } \\
\text { priorities by raising their } \\
\text { awareness } \\
\text { S5O 1: Providing the } \\
\text { necessary hardware } \\
\text { and software platform } \\
\text { to maximize health } \\
\text { participation among } \\
\text { the public and } \\
\text { governmental and non- } \\
\text { governmental } \\
\text { institutions }\end{array}$ & $\begin{array}{l}\text { ST Strategies } \\
\text { S2T1, S3T2 and S4T1: Effective } \\
\text { and purposeful use of the } \\
\text { ability of native health } \\
\text { personnel, liaisons and health } \\
\text { ambassadors to establish an } \\
\text { active and constructive } \\
\text { relationship between the } \\
\text { health system and the } \\
\text { community } \\
\text { S1T3: Careful attention of } \\
\text { managers and officials of } \\
\text { health centers in preventing } \\
\text { philanthropists and } \\
\text { participants abusing of their } \\
\text { social status } \\
\text { S4T5: Training the general } \\
\text { public about the importance } \\
\text { of their participation in } \\
\text { health programs and their } \\
\text { inalienable rights in this } \\
\text { regard } \\
\text { S5T6: Efforts to create a legal } \\
\text { context and prestige public } \\
\text { for people to participate in } \\
\text { the health affairs of their } \\
\text { community } \\
\text { S1T7: Effective and targeted } \\
\text { activity of health center } \\
\text { officials in order to promote } \\
\text { intersectoral support and } \\
\text { cooperation outside the } \\
\text { health sector }\end{array}$ \\
\hline & $\begin{array}{l}\text { Weaknesses (W) } \\
\text { W1: Lack of } \\
\text { understanding of } \\
\text { health conditions and } \\
\text { needs by the relevant } \\
\text { authorities } \\
\text { W2: Lack of knowledge } \\
\text { and skills of some } \\
\text { health managers and } \\
\text { personnel in attracting } \\
\text { the participation of }\end{array}$ & $\begin{array}{l}\text { WO Strategies } \\
\text { W1O1: Entrusting the } \\
\text { management of health } \\
\text { centers to people with } \\
\text { sufficient knowledge } \\
\text { and experience in the } \\
\text { field health } \\
\text { management } \\
\text { W2O1: Empowering } \\
\text { health managers about } \\
\text { the importance and }\end{array}$ & $\begin{array}{l}\text { WT Strategies } \\
\text { W6T1: Holding health sessions } \\
\text { in the evening and at night } \\
\text { shifts or on holidays to allow } \\
\text { employees to participate in } \\
\text { the health affairs } \\
\text { W6T2: Active referral of } \\
\text { health personnel to homes as } \\
\text { well as private and public } \\
\text { institutions to establish } \\
\text { effective communication }\end{array}$ \\
\hline
\end{tabular}




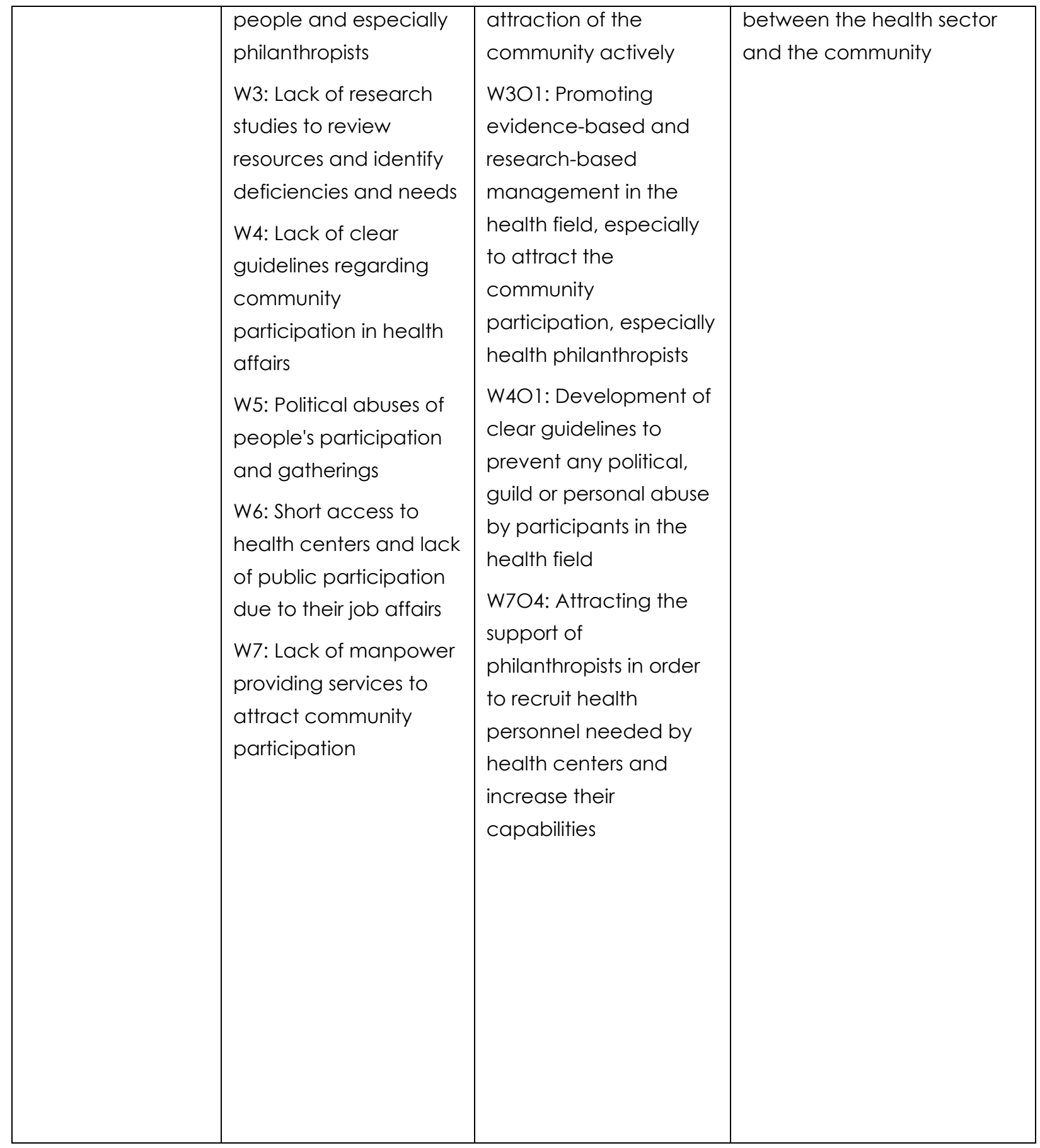

\section{DISCUSSION}

The aim of the present study was to perform a strategic analysis of the internal and external environment of primary health care and presentation of promotion strategies to attract community participation. Analysis of external environment of the field of primary health care in Iran regarding community participation in health affairs led to identification of opportunities such as increasing the level of community literacy and improving the ability of people to participate in health affairs, the possibility of using public spaces to hold conference with the community, the possibility of using media and influential people in the community in encouraging people to take an active part in health affairs as well as the influence of health philanthropists in removing financial constraints in this area.

The most important threat identified included the impossibility of people's participation due to financial constraints and consequently their busy work and family schedule, unfamiliarity of the society with its valuable role in the field of health, political and financial abuse of officials and philanthropists of health gatherings and insufficient participation of organizations which are outside of the health sector. Assessment of the internal environment of primary health care led to the identification of few 
strengths, including native selection policy in the case of health personnel and the existence of relative basic infrastructure for community participation. This assessment also led to the identification of significant weaknesses such as the inefficiency of some health managers, lack of attention to evidence-based performance, absence of community participation due to poor time access to health activities and the lack of health personnel.

Another study conducted in Iran by MohammadiShahbolaghi et al., Introduces issues such as centralization at the community level, separation of government from people, and the lack of equal access to information as the main barriers to community participation [10] Findings of this study also showed a relationship between level of education, hours of leisure time, existence and duration of social participation in the past with the level of social participation of citizens (10). In a study conducted in Saudi Arabia, Abdulhadi referred to illiteracy, low health awareness of citizens, irresponsibility of people towards participation in community health, lack of information needed for health personnel to make decisions, the presence of non-native and non-Arabic speaking health personnel in health system of Saudi Arabia, the tendency of the society towards private medical centers, and the non-participation of women in health affairs as the most important challenges of community participation in health affairs. [23]

Gatewood also divides the factors influencing social nonparticipation to health promotion into individual (monthly income, level of education, leisure and family size) and environmental dimensions (school, work, family and friends). He also refers to self-efficacy of participants as one of the important factors in social participation and believes that people with high self-efficacy are more participatory than others. [24] Existence of committed, experienced and motivated personnel, direct and effective displacement and activity of employees of organizations involved in promoting community health, is an important source for attracting social participation. [25] Organizational management model, introduction of community health promotion interventions and plans [26], management network, managers' resources, and the attitudes of those involved in policymaking are among structuralorganizational factors affecting social participation in health promotion. [27] Overall, it can be claimed that political, legal, legislative, and economic factors affect social participation in health promotion. [27] Kenny et al. have also referred to challenges in defining concepts such as community and participation, the purpose and logic of community participation, disregard for research and creation of evidence related to community participation, determining people participating in the health field, the role of government in attracting community participation, and continuation of this participation. [28]

The most strategies proposed to promote public participation in community health can be summarized and reported as follows. Increasing awareness and empowerment of citizens to participate in health-related activities with the cooperation of the media and influential people, provision of public spaces and facilities, holding participatory meetings, continuous empowerment of health personnel and liaisons, directing and targeting the assistance provided by philanthropists to health priorities. Providing the necessary hardware and software facilities to attract maximum participation of people and governmental and non-governmental institutions in the health field. Entrusting the management of health centres to people with sufficient knowledge and experience. Increasing their skills in attracting community participation, promoting evidence-based and research-centered management in the health field. Developing clear guidelines to prevent any political / guild or personal abuse of those involved in health affairs, active referral of health personnel to people's living environment to obtain their views and support. Improving the timely access to health activities, creating appropriate legal and social contexts for community participation in health affairs, strengthening intra- and inter-sectoral cooperation with individuals and health institutions.

In their study, Mohammadi-Shahbolaghi et al. suggested promotion strategies such as creating a correct image in the authorities regarding the issue of community participation, educating people to have appropriate interpersonal communication and building a collaborative culture, as well as creating the ground needed to promote community participation and thus to increase prosperity in this area. [10] Abdolhadi also suggested the following important promotion strategies to increase community participation in matters related to primary health care: eradicating illiteracy, especially among women, expanding health education through the media, expanding cooperation with local institutions, active referral of health personnel to homes to encourage community participation, creating health-friendly communities, creating appropriate incentives for participants, selection of experienced and preferably 
indigenous health personnel as well as decentralization in the field of primary health care. [23] Draper et al. also referred to creation of appropriate political facilities and conditions for discussion and dialogue between people to reach a single definition of problems, a single decision, public education, and legal and financial support for these programs as important and necessary factors for expansion of community participation. [26]

The effort and accuracy of the research team in selecting the best experts using purposeful sampling and directing the analysis of the external and internal environment of the organization to the point to develop promotion strategies can be considered the strengths of the present study. They are few relevant domestic and foreign studies, and the present study focused only on the community participation in the field of primary care, therefore, the results cannot be fully generalized to other areas of health services, namely treatment and rehabilitation.

\section{CONCLUSION}

The present study showed that there are major problems and challenges in the internal and external environment of primary health care to expand effective community participation in health activities and we can overcome them by relying on the strengths of the health system and external opportunities. Undoubtedly, the results of the present study and the promotion strategies presented can pave the way for managers and policy makers in the field of primary health care in Iran.

\section{ACKNOWLEDGMENT:}

This research is the result of a doctoral dissertation on health services management approved by the Islamic Azad University of Semnan with the Code of Ethics: IR.IAU.Semnan.REC.1396.4. Hereby, the authors would like to express thanks to all professors and colleagues who provided assistance in this research.

\section{References:}

1. WHO-UNICEF. Report of the International Conference on Primary Health Care, Alma Ata. Geneva: World Health Organization (WHO); 1987.

2. Nekoei Moghadam M, Sadeghi V, Parva S. Weaknesses and challenges of primary healthcare system in Iran: a review. Int J Health Plann Mgmt. 2012;27(2):121-31.

3. WHO. The World Health Report. Primary healthcare: now more than ever. Geneva, Switzerland: World Health Organization Publisher; 2008.

4. Gharibi F, Tabrizi JS. Development of an accreditation model for health education and promotion programs in the Iranian primary healthcare system: a Delphi study. Health Promotion Perspectives. 2018;8(2):155-62.

5. Pilehroudi S. District Health Network. Tehran: Razaviieh Publication; 2006.

6. Sadeghi V. Surveying new challenges and weaknesses of Primary Health Care (PHC) system in urban areas of Iran and preparing solutions: Case study in East Azerbayjan. Kerman: Kerman University of Medical Science; 2013.

7. Hall J, Taylor R. Health for all beyond 2000: the demise of the Alma-Ata Declaration and primary health care in developing countries. Med J Aust 2003;178(1):17-20.

8. Reshadat S, Zakiei A, Karimi P, Komasi S. Community participation in health among the general population in Kermanshah city: the predictive role of personality factors and self-efficacy. Community Health. 2017;4(1):42-54.

9. Bolhari J, Zojaji A, Karimi-Kisomi I, Nazari-Jeirani M, Tabaee S. Urban mental health service: primary health care model with community participation. IJPCP. $2011 ; 17(2): 110-5$.

10. MohammadiShahbolaghi F, SetareForuzan A, Hemmati S, Karimlu M. Associated Factors with Community Participation in Health. Social Welfare. 2013;13(48):47-72.

11. Preston R, Waugh H, Larkins S, Taylor J. Community participation in rural primary health care: intervention or approach? Aust J Prim Health. 2010;16(1):4-16.

12. Asadi-Lari M, Sayyari AA, Akbari ME, Gray D. Public health improvement in Iran -lessons from the last 20 years. Pub Health. 2004;1 18(6):395-402. 
13. Helms MM, Nixon J. Exploring SWOT analysis-where are we now? A review of academic research from the last decade. Journal of strategy and management. 2010.

14. Carlsen J, Andersson T. Strategic SWOT analysis of public and private organization. International Journal of Event and Festival Management. 2011;2(1):83-97.

15. Trifonova S, Pramatarov A. SWOT Analysis of the Facility Management of Hospitals: The Case of Bulgaria. Academy of Contemporary Research Journal. 2016;5(1):1-9.

16. Ansary $M$, Rahimi A, Yarmohamadian $M$, Yaghobbi $M$. SWOT Analysis in School of Management and Medical Information Science, Isfahan University of Medical Sciences. Journal of Health Administration. $2009 ; 12(36): 33-8$.

17. Terzic Z, Vukasinovic Z, Bjegovic-Mikanovi V, Jovanovic $V$, Janicic R. SWOT analysis: The analytical method in the process of planning and its application in the development of orthopedic hospital department. Srpski Arhiv Za Celokupno Lekarstvo Journals. 2010;138(7-8):473-9.

18. Ali Taleshi A, Nejadkoorki F, Azimzadeh HR, Ghaneian MT, Namayandeh SM. Strategic Management of Hospital Wastes Using SWOT Method: Case Study of Yazd Educational Hospitals. Journal of health. 2015;6(3):291-303.

19. Aminifard F, Moshkani M. Investigation of occupational health and safety application using the internal and external factor assessment matrix: SWOT. JHSW. 2012;2(2):53-60.

20. Jackson SE, Joshi A, Erhardt NL. Recent Research on Team and Organizational Diversity: SWOT Analysis and Implications. Journal of Management. 2003;29(6):80130.

21. Agarwal R, Grass W, Pahl J. Meta-Swot: introducing a new strategic planning tool. Journal of Business Strategy. 2012;33(2):12-21.

22. Aslan I, Çınar O, Özen Ü. Developing Strategies for the Future of Healthcare in Turkey by Benchmarking and SWOT Analysis. Procedia-Social and Behavioral Sciences. 2014;150(3):230-40.

23. Abdel-Hadi AH, AL-Borie HM. Health Care and Proposed Solutions in Two Major Saudi Cities. JKAU. 1994;7:3-156.

24. Gatewood JG, Litchfield RE, Ryan SJ, Geadelmann JD, Pendergast JF, Ullom KK. Am J Health Behav.
Perceived barriers to community-based health promotion program participation. 2008;32(3):260-71.

25. Branson R, Davis K, Butler K. African-American participation in clinical research: importance, barriers and solutions. The American journal of surgery. 2003; 193(1):32-9.

26. Draper AK, Hewitt G, Rifkin S. Chasing the dragon: developing indicators for assessment of community participation in health programs. Social science \& medicine. 2010;71(6):1102-9.

27. Boyce W. Disadvantage's persons' participation in health promotion projects: some structural dimensions. Social Science \& Medicine. 2001;52(10):1551-64.

28. Kenny A, Farmer J, Dickson-Swift V, Hyett N. Community participation for rural health: a review of challenges. Health Expectations. 2015;18(6):1906-17. 